Document downloaded from:

http://hdl.handle.net/10251/145862

This paper must be cited as:

Gil-Castell, O.; Badia, J.; Ribes-Greus, A. (04-2). Tailored electrospun nanofibrous polycaprolactone/gelatin scaffolds into an acid hydrolytic solvent system. European Polymer Journal. 101:273-281. https://doi.org/10.1016/j.eurpolymj.2018.02.030

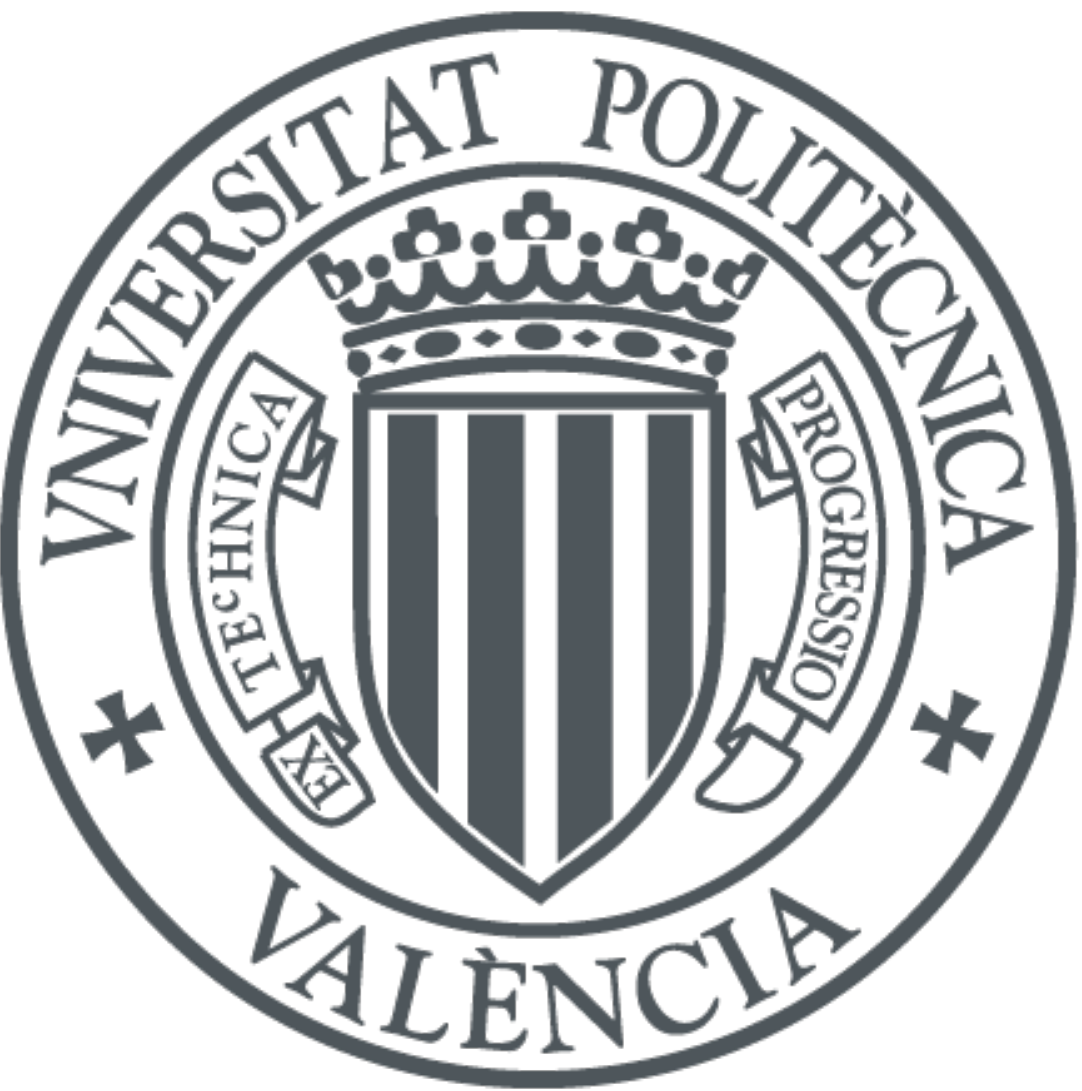

The final publication is available at

https://doi.org/10.1016/j.eurpolymj.2018.02.030

Copyright Elsevier

Additional Information 


\title{
TAILORED ELECTROSPUN NANOFIBROUS POLYCAPROLACTONE/GELATIN SCAFFOLDS INTO AN ACID HYDROLYTIC SOLVENT SYSTEM
}

\author{
O. Gil-Castell ${ }^{1}$, J. D. Badia ${ }^{1,2}, \underline{\text { A. Ribes-Greus }}{ }^{1, *}$
}

\begin{abstract}
Blended nanofibrous scaffolds based on polycaprolactone (PCL) and gelatin (Ge) were successfully prepared. A formic/acetic acid (1:1) mixture was used to dissolve PCL/Ge blends from $100 / 0$ to $20 / 80 \%$ wt in steps of $10 \%$ wt. The hydrolysis of the PCL diluted in the formic/acetic acid mixture was considered as a method for tailoring the surface morphology and physicochemical features of the nanofibrous PCL/Ge scaffolds as a function of the dissolution time. The fibre diameter remained in the nanoscale range for all the studied scaffolds, which is crucial to mimic the extra-cellular matrix size. The reduction of the intrinsic viscosity, molar mass and hydrodynamic radius found for the PCL molecules as a function of the dissolution time, consequently diminished the entanglement capability of the polymeric chains. Subsequently, the fibre diameter decreased as dissolution time increased, for all the studied compositions. While the crystallinity of the scaffolds with high PCL content increased as a function of the dissolution time, the scaffolds with high percentage of Ge showed the lowest crystallinity degree, which was ascribed to the hindering effect of the Ge diffused among the PCL segments. The wettability increased as a function of the Ge content due to the high hydrophilic behaviour of these molecules. It also increased as a function of the dissolution time, due to the more hydroxyl groups available in PCL segments to interact with water molecules. As a whole, the physicochemical assessment of the electrospun scaffolds revealed an effective tailoring procedure to obtain functionalised $\mathrm{PCL} / \mathrm{Ge}$ scaffolds with specific properties as a function of the dissolution time before electrospinning.
\end{abstract}

\section{Keywords}

Electrospinning; scaffold; polycaprolactone (PCL); gelatin (Ge); tailoring; hydrolysis 


\section{Introduction}

Tissue engineering involves the combination of engineering, materials and cells to improve or replace biological tissues. One of the fundamental approaches of this field is the fabrication of biocompatible scaffolds that provide the optimum conditions for cell adhesion and proliferation along with tailored durability and performance. The development of synthetic nanoscaled fibrous scaffolds that structurally mimic extra-cellular matrix (ECM) in size and porosity has brought new possibilities in the field of tissue regeneration [1].

The processing techniques to obtain artificial tissues are in continuous development [2]. Electrospinning stands out as one of the most promising techniques for the preparation of polymeric nanofibrous devices [3]-[5]. This method offers non-woven nanofibrous scaffolds with large area-to-surface ratio and high porosity that have fulfilled novel biomedical requirements [6], [7].

A variety of natural and synthetic polymers have been used for nanofibrous scaffold fabrication, including polycaprolactone, poly(lactic acid), poly(glycolic acid) and their copolymers [8]-[11]. Among them, polycaprolactone (PCL) is a semicrystalline linear aliphatic polyester, widely applied in biomedicine due to its good mechanical properties, biocompatibility and slow biodegradability, being suitable for applications which require certain structural durability [12][17]. However, the lack of hydrophilic functional groups in the chemical structure of the PCL macromolecules have prevented this material from an extended application as an individual component. Several strategies such as coating, grafting or blending with other components have been suggested in order to improve the cell affinity of the scaffolds [18]. Actually, several hydrophilic biopolymers including collagen, gelatin, fibrinogen or elastin have been considered to improve the scaffold hydrophilicity and biocompatibility [19]. Gelatin (Ge) is a natural biopolymer of excellent biocompatibility, biodegradability and low cost in comparison to collagen. It contains Arginyl-Glycyl-Aspartic amino acid sequence, which offers biochemical signals to promote cell adhesion, migration, proliferation and differentiation [20]. Thus, the combination of PCL and Ge into a nanofibrous scaffold would retain the mechanical properties of PCL with an improved cell affinity brought by the Ge. Actually, PCL/Ge nanofibrous scaffolds have been proposed as a versatile substrate for cell seeding of different tissues, including skin [21]-[26], muscle [27], cardiovascular [28], [29], nerve [30]-[32], bone [33]-[36] and cartilage [37], [38].

The suitability of the electrospinning process is known to depend on the synergistic effect of the solution and processing conditions [39]-[41]. Traditionally, highly toxic halogenated solvents such as chloroform, hexafluoroisopropanol, trifluoroethylene, dimethylformamide, methylene chloride or dichloroethane have been required for the effective electrospinning of PCL and Ge 
[40], [42], [43]. In the last years, some alternative solvents such as acetone [44], acetic acid [45], acetic acid/ethyl acetate [46], tetrahydrofuran/methanol [47], tetrahydrofuran [40] or formic/acetic acid mixture [48]-[50] have been proposed for the electrospinning of the PCL. These solvents allow minimizing the risk to health during manipulation [51] and reduce the toxicity of the scaffolds due to retained residual solvent [52]. For the electrospinning of Ge, lowtoxic alternative solvents have also been considered, including acetic acid [53], [54] or ethylacetate/acetic acid in water [55]. Specifically, the formic/acetic mixture has been considered as a suitable candidate for the electrospinning of PCL/Ge scaffolds [56]-[59].

Some studies in the bibliography correlate the influence of several features of the scaffolds on their subsequent performance such as the composition, the fibre diameter, the scaffold porosity, the molar mass, the glass transition temperature or the crystallinity degree, among others [60][65]. The hydrolytic degradation of the PCL molecules in the formic/acetic mixture and results in the reduction of the polymer molar mass, and thus some of the physicochemical properties of the electrospun scaffolds could be expected to be altered as a function of the dissolution time [49]. Indeed, the physicochemical behaviour of PCL/Ge scaffolds has not been correlated to the dissolution time of the polymer in the formic/acetic acid solution before electrospinning, and therefore represents an interesting line of research for the tailoring of biomedical scaffolds.

The aim of this study was therefore to obtain tailored nanofibrous PCL/Ge scaffolds in terms of the blend composition and the dissolution time into a hydrolytic formic/acetic acid (1:1) solvent, and correlate them with the impact on the structure, morphology and performance of these scaffolds.

\section{Materials and methods}

\subsection{Materials}

Polycaprolactone (PCL) was supplied by Perstorp as $3 \mathrm{~mm}$ diameter pellets under the grade CAPA $^{\text {тм }} 6800\left(M_{n}=85000 \mathrm{~g} \cdot \mathrm{mol}^{-1}\right.$ and $\left.T_{m} 58-60^{\circ} \mathrm{C}\right)$. Gelatin $(\mathrm{Ge})$ from porcine skin Type A, gel strength 300, was supplied by Sigma-Aldrich. Formic acid and acetic acid ( $\geq 99 \%)$ were used as solvents for electrospinning. Tetrahydrofuran ( $\geq 99.8 \%)$ was used for SEC sample preparation and analysis. All solvents were supplied by Sigma-Aldrich and were used without further purification.

\subsection{Polymer solution and electrospinning}

Nine blended compositions of PCL/Ge were prepared, ranging from 100/0 to 20/80 by weight proportion, by steps of $10 \%$ wt. The solutions for electrospinning were prepared in a 1:1 formic/acetic acid mixture, with a total solid concentration of $15 \%$ wt and were electrospun after 
being subjected to $30^{\circ} \mathrm{C}$ and magnetic stirring for $24,48,72,96$ and $120 \mathrm{~h}$. The dissolution time ranged between the minimum time to reach complete dissolution $(24 \mathrm{~h})$ and the time in which the viscosity of the solution still ensured stable electrospinning $(120 \mathrm{~h})$.

Nanofibrous scaffolds were obtained by means of a Bioinicia FLUIDNATEK ${ }^{\circledR}$ LE-10 electrospinning equipment, which contents a high voltage source, a programmable syringe pump, a HSW NORM-JECT $20 \mathrm{~mL}$ Luer Lock syringe, a Teflon ${ }^{\circledR}$ tubing, a gauge 21 metallic needle and a grounded flat collector. The tip-to-collector distance was maintained constant at $15 \mathrm{~cm}$. The feeding rate and voltage varied as dissolution time increased between 1 to $0.2 \mathrm{~mL} \cdot \mathrm{h}^{-1}$ and 25 to $19 \mathrm{kV}$, respectively. The working time was adjusted for each case as a function of the feeding rate in order to obtain nanofibrous structures with comparable surface density. The temperature and relative humidity $(\mathrm{RH})$ were kept constant along electrospinning at $22{ }^{\circ} \mathrm{C}$ and $35 \% \mathrm{RH}$, respectively. The nanofibrous scaffolds were collected on waxed paper, dried and stored for further analyses.

\subsection{Scaffold characterization}

\subsubsection{Field-emission scanning electron microscopy (FE-SEM)}

The surface topology of the specimens was analysed by means of a Zeiss Ultra 55 field emission scanning electron microscope (FE-SEM). The samples were cut into small pieces and dried at 50 ${ }^{\circ} \mathrm{C}$ in a vacuum oven for $24 \mathrm{~h}$ and then kept in a desiccator during $48 \mathrm{~h}$. Afterwards, the specimens were mounted on metal studs and sputter-coated with a platinum layer during $10 \mathrm{~s}$ using a Leica EM MED020 sputter coater. FE-SEM images were taken at $22^{\circ} \mathrm{C}$ with a $2 \mathrm{kV}$ voltage. The fibre diameters were measured from the scanning electronic microscope images $(10000 \times)$ at random locations $(n=100)$ with the aid of the Image $\mathrm{J} 囚$ software.

\subsubsection{Thermogravimetric analysis (TGA)}

The thermo-oxidative decomposition profiles were obtained by means of a Mettler-Toledo TGA 851 thermogravimetric analyser. The samples, with a mass of about $4 \mathrm{mg}$ were introduced in TGA Mettler-Toledo perforated alumina crucibles, with capacity of $70 \mu$. The samples were analysed in the temperature range of 25 to $800{ }^{\circ} \mathrm{C}$ with a heating rate of $10{ }^{\circ} \mathrm{C} \cdot \mathrm{min}^{-1}$, under atmosphere of oxygen at a flow rate of $50 \mathrm{ml} \cdot \mathrm{min}^{-1}$. The experiments were performed in triplicates to ensure reproducibility.

\subsubsection{Size exclusion chromatography (SEC)}

Size exclusion chromatography (SEC) was carried out by means of a Malvern Instruments OMNISEC RESOLVE chromatograph. It combined an integrated pump, a degasser, an autosampler and a column oven, along with a Malvern Instruments OMNISEC REVEAL multi- 
detector-Ultraviolet (UV), Refractive Index (RI), Low and Right Angle Light Scattering (LALS and RALS) and Viscosity (VISC)-. A monodisperse polystyrene standard with $\mathrm{dn} / \mathrm{dc}$ value of 0.185 was used for universal calibration. Two columns from Malvern Instruments (T2000 and T4000) were used $(300 \times 8 \mathrm{~mm})$. Tetrahydrofuran (THF) was used as mobile phase at a flow rate of $1 \mathrm{~mL} \cdot \mathrm{min}^{-1}$ and a column temperature of $35^{\circ} \mathrm{C}$. The samples were dissolved in THF with concentrations of around $2.0 \mathrm{mg} \cdot \mathrm{ml}^{-1}$ and filtered through $0.45 \mu \mathrm{m}$ PTFE filters. Two specimens per sample were analysed and the obtained data were assessed in triplicates with the aid of the OMNISEC V10 ${ }^{\mathrm{TM}}$ software, and the averages were taken as representative values.

\subsubsection{Differential scanning calorimetry (DSC)}

The calorimetric data were obtained by means of a Mettler-Toledo DSC $820^{\mathrm{e}}$ differential scanning calorimeter, previously calibrated following the procedure of In and $\mathrm{Zn}$ standards. The samples, with a mass of about $4 \mathrm{mg}$, were analysed between 0 and $80{ }^{\circ} \mathrm{C}$ with a heating/cooling/heating rate of $10^{\circ} \mathrm{C} \cdot \mathrm{min}^{-1}$. All the experiments were run under nitrogen atmosphere at $50 \mathrm{~mL} \cdot \mathrm{min}^{-1}$. The specimens were characterised at least by triplicate and the averages of temperatures and enthalpies were taken as representative values.

The crystallinity degree $\left(X_{c}\right)$ was evaluated from the melting enthalpy results, by means of the Equation 1,

$$
X_{C}(\%)=\frac{\Delta h_{m}}{w_{P C L} \cdot \Delta h_{m}^{0}} \cdot 100
$$

where $\Delta h_{m}$ is the melting enthalpy of the PCL melting, $w_{P C L}$ is the weight fraction of the PCL in the sample and $\Delta h_{m}{ }^{0}$ is the melting enthalpy of a perfect crystal of PCL $\left(148 \mathrm{~J} \cdot \mathrm{g}^{-1}\right)$ [66].

\subsubsection{Water contact angle}

The wettability of the scaffolds was characterized according to its water contact angle at $22{ }^{\circ} \mathrm{C}$. The static contact angle was evaluated by means of a Theta Optical Tensiometer (KSV Instruments, Ltd) and a CCD (charge-coupled device) camera connected to a computer. $2 \mu \mathrm{L}$ of distilled water were dropped on the sample surface and, after $2 \mathrm{~s}$, the contact angle was measured. The assays were repeated at three different sites of a given sample to ensure reproducibility.

\section{Results and discussion}

\subsection{Validation of the electrospinning strategy}

In order to validate the scaffold composition, the study of the thermo-oxidative decomposition behaviour was considered as an appropriate methodology, as proposed by Gautam et al. [67]. The 
thermo-oxidative decomposition profiles as a function of the scaffold composition are plotted in

\section{Figure 1.}

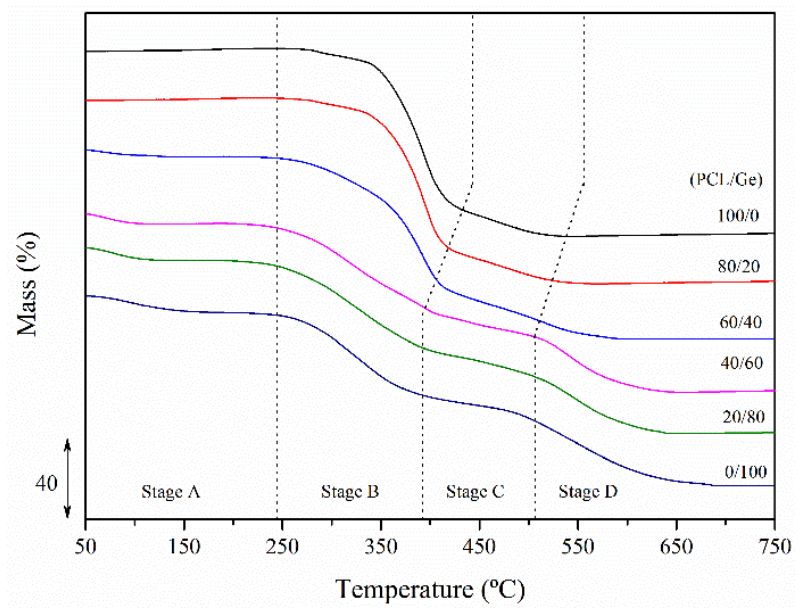

Figure 1. Thermo-oxidative decomposition profiles of electrospun scaffolds as a function of the scaffold composition $(\mathrm{PCL} / \mathrm{Ge})$ for a dissolution time of $24 \mathrm{~h}$.

Pure PCL (100/0) showed a multiple stage decomposition performance. Humidity loss was observed in stage A, and primarily decomposition was found in stage B, followed by a secondary decomposition in stage $\mathrm{C}$, reaching complete decomposition between $350{ }^{\circ} \mathrm{C}$ and $520{ }^{\circ} \mathrm{C}$, as corroborated by literature [67], [68]. The decomposition profile of pure Ge (0/100) consisted of multiple stages. The vaporization of moisture took place between 50 and $230{ }^{\circ} \mathrm{C}$ in the stage $\mathrm{A}$, while the main decomposition stage occurred between $250^{\circ} \mathrm{C}$ and $400{ }^{\circ} \mathrm{C}$ in the stage $\mathrm{B}$. Then the thermo-oxidative decomposition continued until $600{ }^{\circ} \mathrm{C}$ in the stages $\mathrm{C}$ and $\mathrm{D}$. This multiple stage behaviour was ascribed to a complex thermo-oxidative decomposition process that involves protein rupture and breakage of the peptide bond, in line with previous research [34], [69].The scaffolds showed an intermediate behaviour combining the thermo-oxidative decomposition stages of both pure components. The increase of the Ge content progressively displaced the onset of the decomposition towards lower temperatures as well as promoted the decomposition in stages A and D [26]. Although the main degradation stages of the PCL and Ge in the scaffolds were overlapped, the study of the horizontal step for each stage, especially for stages B and D, revealed a progressive behaviour as a function of the scaffold composition, as gathered in Table 1. According to bibliography, this phenomenon suggested a blending interaction between both components through hydrogen bonding between the ester group of the PCL and the amine group of Ge molecules within the scaffold [26], [67], [70]. 
Table 1. Mass loss (\%) in the different stages during thermo-oxidative decomposition of electrospun scaffolds for a dissolution time of $24 \mathrm{~h}$. Standard deviation between 3 and $5 \%$ omitted for the sake of clarity.

\begin{tabular}{ccccc}
\hline $\begin{array}{c}\text { (PCL/Ge) } \\
(\% \text { wt })\end{array}$ & Stage A & Stage B & Stage C & Stage D \\
\hline $100 / 0$ & - & 88.04 & 10.91 & - \\
\hline $80 / 20$ & - & 75.60 & 10.59 & 8.79 \\
\hline $60 / 40$ & 1.00 & 73.55 & 11.49 & 10.62 \\
\hline $40 / 60$ & 4.05 & 68.28 & 11.26 & 13.92 \\
\hline $20 / 80$ & 7.02 & 46.65 & 10.80 & 31.27 \\
\hline $0 / 100$ & 8.15 & 40.77 & 9.38 & 38.28
\end{tabular}

The scanning electron microscope images of the electrospun scaffolds as a function of the PCL/Ge composition and dissolution time are shown in Figure 2. Practicable scaffolds ( $\star$ ), i.e, scaffolds which were adequately handled without mechanical disaggregation of fibres, were found after 24 $\mathrm{h}$ and $48 \mathrm{~h}$ of dissolution for all the studied compositions. However, as dissolution time increased, the scaffold usability was altered as perceived by the formation of ultra-thin fibres and microscaled beads. Nevertheless, the increase of the Ge content improved the electrospinning viability after high dissolution times, giving rise to more stable and practicable scaffolds.

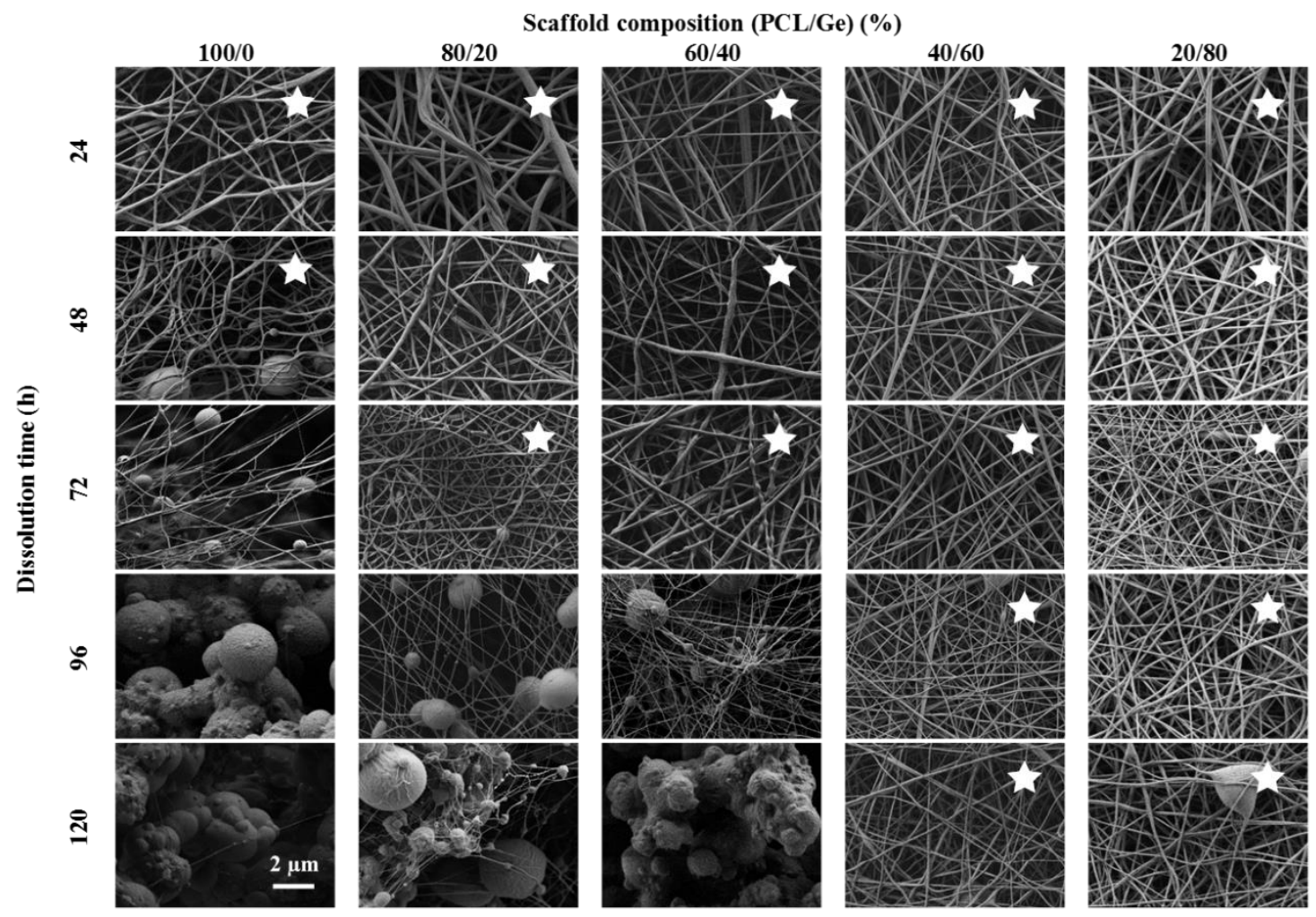

Figure 2. FE-SEM images $(10000 \times)$ of electrospun scaffolds as a function of the scaffold composition and the dissolution time. ( $\star$ Refer to the practicable scaffolds. 


\subsection{Hydrolytic degradation of the PCL fraction}

It is well known that suitable electrospinning depends on the confluence of several conditions and requirements [39]. Among them, one of the main factors is the solution viscosity, which is in turn affected by several elements such as the solution concentration, the polymer molar mass or the temperature [5]. Since the solid concentration (15\%wt) and the temperature remained constant, the hypothetic molar mass reduction due to the PCL chain scission may have resulted in excessively low viscosity for suitable electrospinning after high dissolution time. Although the hydrolysis and subsequent viscosity reduction of the Ge as a function of time when diluted in formic acid has been reported by Ki et al. [71], the addition of Ge to the blend may have contributed to retain enough viscosity for suitable electrospinning, particularly for high dissolution times, when the PCL molecules were severely hydrolytically degraded.

In order to evaluate the change in the molar mass of the PCL fraction of the scaffolds when diluted into the formic/acetic mixture, size exclusion chromatography (SEC) measurements were conducted regardless the formation of practicable electrospun scaffolds. The molar mass distributions are plotted in Figure 3a as a function of the dissolution time for all PCL/Ge compositions. When the dissolution time increased, a displacement of the molar mass distributions towards lower values was observed, due to hydrolytic degradation of the ester bond and subsequent chain scission [49], as visually suggested during the electrospinning solution preparation. The chain scission is frequently terminated by carboxylic acid end groups and hydroxyl end groups [72]. The hydrolytic reaction may occur as a depolymerisation process and random chain scission mechanism, highly catalysed by the formic/acetic acid solution.

Two different behaviours could be distinguished, depending on the prevalence of one component or the other in the scaffold. For scaffolds with high PCL content, a low molar mass peak (around $10000 \mathrm{~g} \cdot \mathrm{mol}^{-1}$ ) appeared and increased for high dissolution times, turning the original unimodal distribution into a bi-modal pattern. In contrast, for scaffolds with high Ge content, a complex multi-modal behaviour was found, attributed to the emulsion of PCL into the Ge matrix diluted in the formic/acetic acid mixture [57]. The dissimilar hydrolytic degradation of the PCL during dissolution in the acidic mixture may be ascribed to the formation of a disperse phase (PCL) into a continuous matrix (Ge), as reported by Kolbuk et al. [59].

The evolution of the average molar mass in number $\left(M_{n}\right)$, the intrinsic viscosity $(I V)$ and the hydrodynamic radius $(R h)$, respectively, are shown in Figure $\mathbf{3 b}, \mathbf{3 c}$ and $\mathbf{3 d}$ through $3 \mathrm{D}$ plots as a function of the blend composition and dissolution time. 
a)
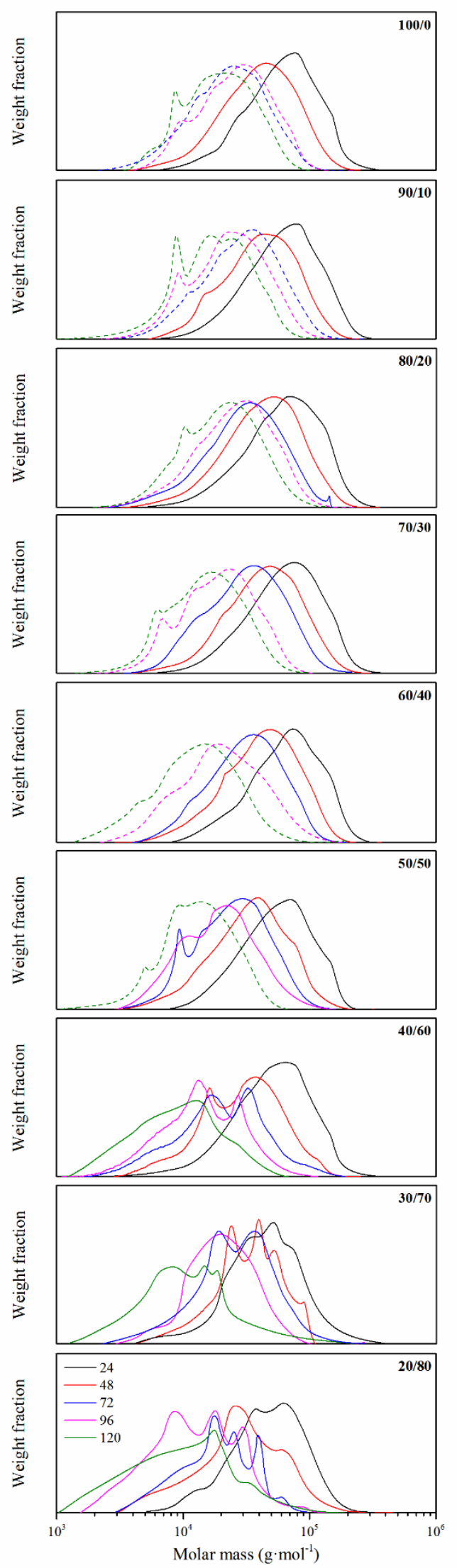

b)

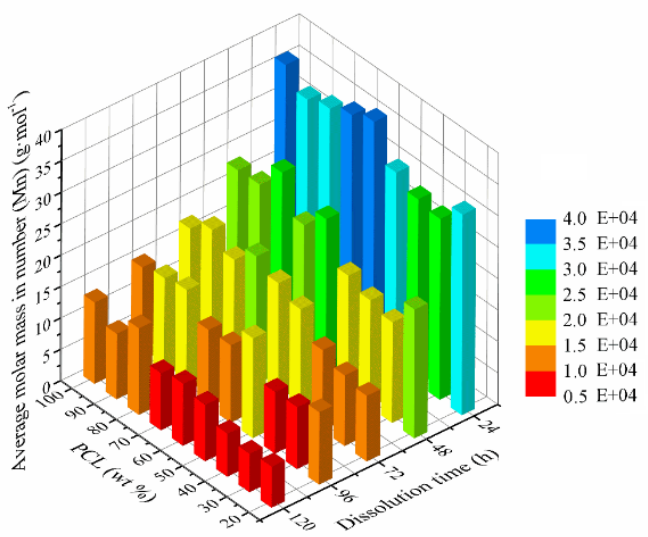

c)

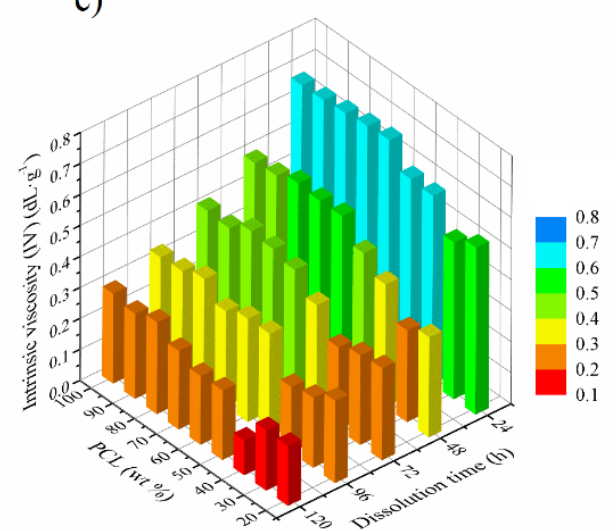

d)

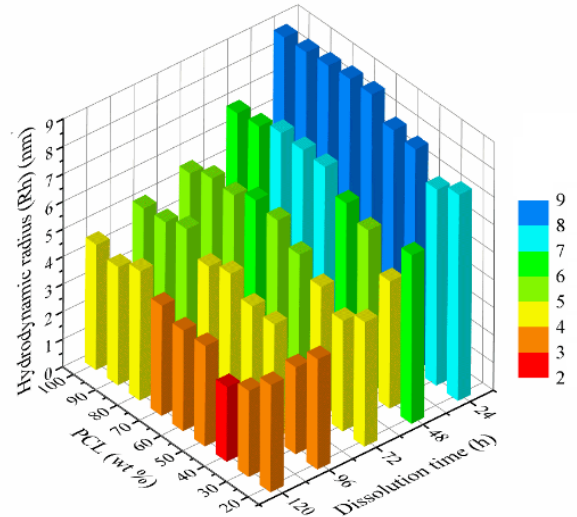

Figure 3. (a) Molar mass distributions as a function of the dissolution time for the different PCL:Ge compositions. Dash lines stand for non-practicable scaffolds; (b) Average molar mass; (c) Intrinsic viscosity; and (d) Hydrodynamic radius as a function of the scaffold composition and dissolution time. 
The analysis of the intrinsic viscosity $(I V)$ and the hydrodynamic radius $(R h)$ of the PCL in the solvent used for the chromatographic analyses (THF) corroborated the hydrolytic degradation of the polymer. A reduction of the polymer chain length promoted lower number of macromolecular entanglements, which is closely related to the $I V$, and lower apparent size, associated to the $R h$. Shorter and smaller macromolecules exhibited lower equivalent radius as dissolution time increased.

The average molar mass in number $\left(M_{n}\right)$ values for the practicable and non-practicable conditions are gathered in Table 2. An estimation of the critical PCL molar mass to get suitable scaffolds for a given solution concentration can be thus established for the different scaffold compositions and dissolution times. The $M_{n}$ significantly decreased as a function of the dissolution time, especially after $24 \mathrm{~h}$ of dissolution. The lowest $M_{n}$ values were found for the scaffolds with high Ge percentage, electrospun after $120 \mathrm{~h}$ of dissolution.

Table 2. The average molar mass in number $\left(M_{n}, \mathrm{~g} \cdot \mathrm{mol}^{-1}\right)$ of the PCL fraction for the practicable and non-practicable (italics) conditions. Standard deviation between 2 and 5\% omitted in the table for the sake of clarity. D.T. stands for dissolution time.

\begin{tabular}{cccccccccc}
\hline \multirow{2}{*}{$\begin{array}{c}\text { D.T. } \\
\text { (h) }\end{array}$} & $\mathbf{1 0 0 / \mathbf { 0 }}$ & $\mathbf{9 0 / 1 0}$ & $\mathbf{8 0 / 2 0}$ & $\mathbf{7 0 / 3 0}$ & $\mathbf{6 0 / 4 0}$ & $\mathbf{5 0 / 5 0}$ & $\mathbf{4 0 / 6 0}$ & $\mathbf{3 0 / 7 0}$ & $\mathbf{2 0 / 8 0}$ \\
\hline $\mathbf{2 4}$ & 36000 & 33000 & 34000 & 35500 & 36900 & 31200 & 29400 & 28900 & 31900 \\
\hline $\mathbf{4 8}$ & 22900 & 23100 & 27500 & 21600 & 25000 & 18500 & 17000 & 16000 & 20500 \\
\hline $\mathbf{7 2}$ & 17700 & 19600 & 17300 & 19200 & 18500 & 16800 & 12100 & 11200 & 11500 \\
\hline $\mathbf{9 6}$ & 14800 & 15600 & 15100 & 13000 & 12300 & 12900 & 12800 & 9900 & 10500 \\
\hline $\mathbf{1 2 0}$ & 12900 & 11400 & 13400 & 9900 & 9100 & 8300 & 6900 & 6100 & 6600 \\
\hline
\end{tabular}

\subsection{Scaffold characterisation}

\subsubsection{Surface morphology}

The analysis of the morphology of the practicable electrospun scaffolds was performed in terms of the fibre diameter, from scanning electron microscope images. The fibre diameter distributions are represented in Box-Whisker plots in Figure $\mathbf{4}$ as a function of the scaffold composition and the dissolution time.

The fibre diameter remained in the nanoscale range for all the studied scaffolds, which is crucial to mimic the extra-cellular matrix size, an essential requirement for satisfactory cell attachment and proliferation [6]. Moreover, the fibre diameter obtained from the electrospinning of the formic/acetic acid solution was lower to that found by other authors that used traditional halogenated solvents [25], [26], [34], [36], [67], [73], [74]. Unimodal distributions were found regardless the composition with average values between 100 and $200 \mathrm{~nm}$ for scaffolds prepared after $24 \mathrm{~h}$ of dissolution. For a given composition, thinner fibres were observed with mean 
diameter with lower standard deviation as a function of the dissolution time. It is interesting to note that the fibre diameter of the scaffolds obtained after the longest practicable dissolution time decreased to about half of the initial value $(75-100 \mathrm{~nm})$. Although several factors such as temperature, feeding rate or voltage may influence the fibre diameter during electrospinning, the reduction in the solution viscosity can be ascribed as the main cause of the fibre diameter decrease. This fact revealed lower molar masses and smaller hydrodynamic radiuses, which produced the subsequent lower entanglement capability and resulted in nanostructured scaffolds with lower fibre diameter.

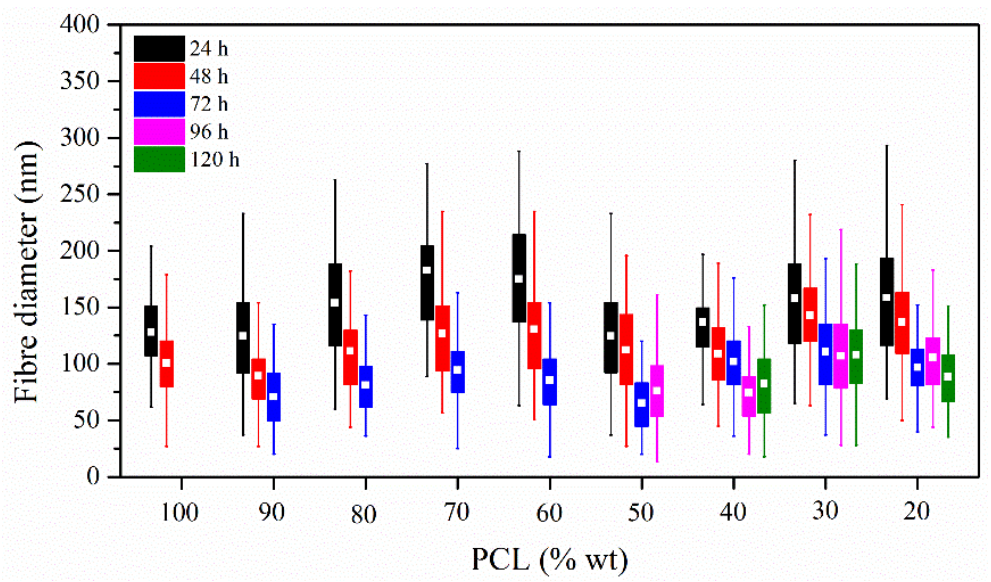

Figure 4. Fibre diameter distributions of the practicable electrospun scaffolds as a function of the scaffold composition and the dissolution time.

\subsubsection{Thermal properties}

Calorimetric analyses were conducted on the nanofibrous PCL/Ge scaffolds in order to study the fibre microstructure by the characterisation of the crystalline population, which is known to play a key role during the nanofibrous scaffold application [75]. The use of the differential scanning calorimetry (DSC) is essential to understand the thermal properties of the biopolymers subjected to different degrading conditions [76]-[80]. Indicators of the degradation such as the partial melting areas [77], the crystallinity degree [81], the relative partial crystallinity [82] or the balance among amorphous and rigid amorphous fractions [83] have been previously proposed for monitoring the degradation of some biopolymers. In this study, the balance between the evolution of the crystallinity degree and the lamellar thickness offers interesting discussion, as shown hereinafter. The calorimetric traces of the first heating scan for the different compositions and dissolution times are shown in Figure 5. 


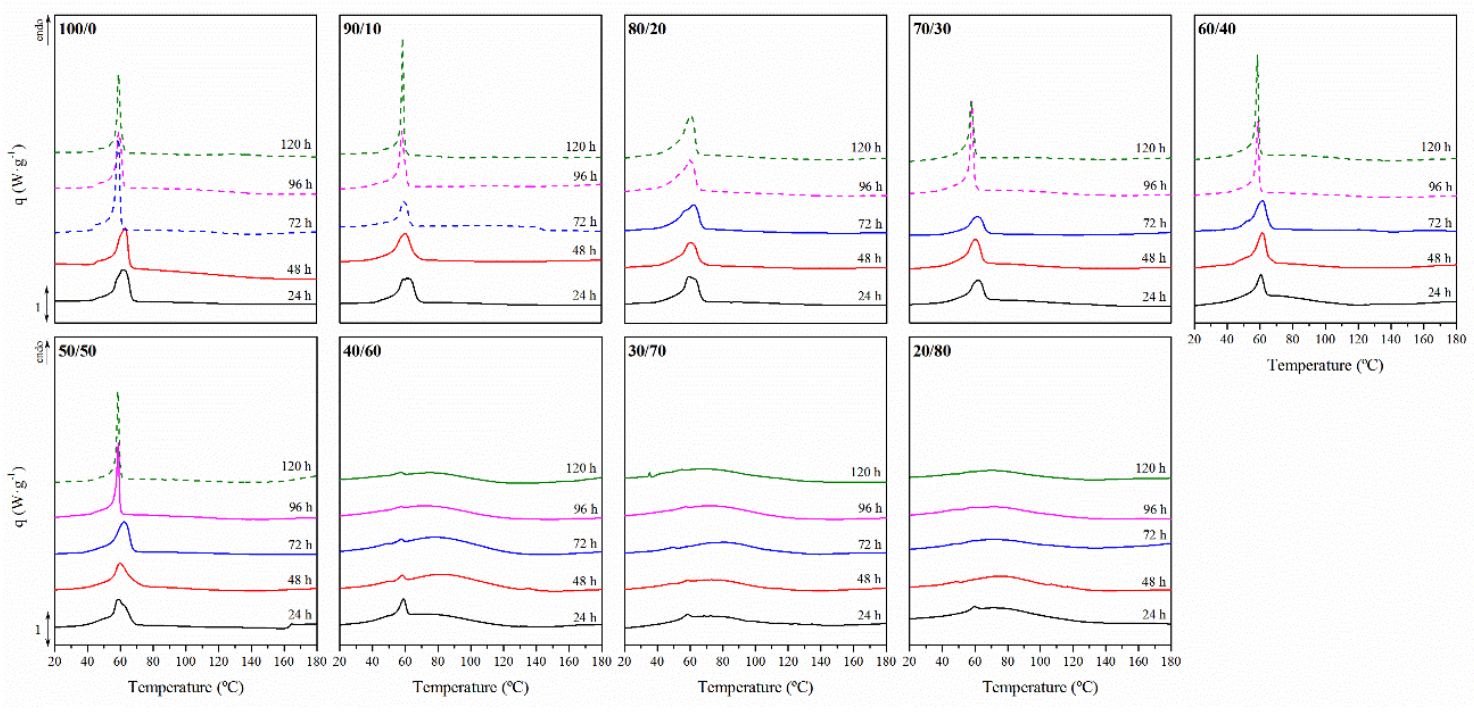

Figure 5. DSC first-heating traces of electrospun scaffolds as a function of the scaffold composition and the dissolution time. Dash lines are used for the non-practicable scaffolds.

A general overview of the DSC thermograms showed different melting behaviours depending on the composition of the scaffolds, in line with the observation of Kolbuk et al. through polarized optical microscopy [59]. For the PCL/Ge scaffolds with compositions ranging from 100/0 to 50/50, a typical semicrystalline behaviour was perceived. They showed a melting transition associated to PCL $\left(\sim 62^{\circ} \mathrm{C}\right)$ that moved towards lower values as the PCL content decreased [57]. Then, an almost negligible wide endotherm from 20 to $120^{\circ} \mathrm{C}$ associated to the water release from Ge molecules was observed [57]. For the 40/60, 30/70 and 20/80 scaffolds, the melting behaviour associated to the PCL crystalline population moved towards lower temperatures until disappearance, while the wide endotherm from 20 to $120{ }^{\circ} \mathrm{C}$ gained importance. The melting temperatures $\left(T_{m}\right)$ for all compositions are gathered in Table 3. Since the characteristic peak of the helix to random coil transition of the $\mathrm{Ge}\left(225^{\circ} \mathrm{C}\right)$ was not observed for these scaffolds, a random coil conformation of the Ge was expected [34]. Therefore, the formic/acetic acid mixture used as solvent for electrospinning may have denaturalised the helix conformation to random coil [45], [71].

As the dissolution time increased, the melting temperature of the PCL decreased for all compositions. The melting events were revealed sharper and displaced towards lower temperatures. Shorter PCL molecules caused by the advance of the hydrolytic degradation resulted in the formation of crystalline domains that melted at lower temperatures. This observation suggested that the hydrolytic degradation of the PCL molecules resulted in lower lamellar thickness and more concise crystalline populations, according to our previous results [49]. 
Table 3. PCL melting temperatures $\left(T_{m},{ }^{\circ} \mathrm{C}\right)$ as a function of the scaffold composition and the dissolution time. D.T. stands for dissolution time.

\begin{tabular}{cccccccccc}
\hline \multirow{2}{*}{$\begin{array}{c}\text { D.T. } \\
\text { (h) }\end{array}$} & $\mathbf{1 0 0 / 0}$ & $\mathbf{9 0 / 1 0}$ & $\mathbf{8 0 / 2 0}$ & $\mathbf{7 0 / 3 0}$ & $\mathbf{6 0 / 4 0}$ & $\mathbf{5 0 / 5 0}$ & $\mathbf{4 0 / 6 0}$ & $\mathbf{3 0 / 7 0}$ & $\mathbf{2 0 / 8 0}$ \\
\hline 24 & $61.6 \pm 0.4$ & $61.7 \pm 1.1$ & $60.5 \pm 1.2$ & $61.0 \pm 0.8$ & $60.8 \pm 0.4$ & $59.0 \pm 0.6$ & $59.6 \pm 0.1$ & $58.9 \pm 0.4$ & $59.7 \pm 0.1$ \\
\hline 48 & $63.2 \pm 0.2$ & $61.5 \pm 0.1$ & $60.4 \pm 0.1$ & $60.3 \pm 0.1$ & $62.8 \pm 0.1$ & $58.7 \pm 0.0$ & $58.1 \pm 0.2$ & $58.5 \pm 0.1$ & $58.1 \pm 0.5$ \\
\hline 72 & $58.4 \pm 0.1$ & $58.6 \pm 0.4$ & $62.0 \pm 0.1$ & $61.1 \pm 0.5$ & $61.3 \pm 0.1$ & $62.1 \pm 0.1$ & $57.3 \pm 0.4$ & $59.2 \pm 0.2$ & - \\
\hline 96 & $59.1 \pm 0.1$ & $58.3 \pm 0.3$ & $60.8 \pm 0.5$ & $58.5 \pm 0.3$ & $58.8 \pm 0.1$ & $58.0 \pm 0.1$ & $57.6 \pm 0.2$ & $58.6 \pm 0.1$ & - \\
\hline 120 & $58.8 \pm 0.1$ & $58.5 \pm 0.1$ & $60.3 \pm 0.2$ & $57.7 \pm 0.1$ & $58.3 \pm 0.1$ & $58.2 \pm 0.2$ & $57.3 \pm 0.0$ & $55.1 \pm 0.5$ & -
\end{tabular}

The evolution of the crystallinity degree $\left(X_{c}\right)$ for practicable scaffolds is plotted in Figure 6. There, the influence of the PCL and Ge concentration was perceived. For the scaffolds with PCL/Ge compositions ranging from 100/0 to 50/50, an increasing tendency of the $X_{c}$ was perceived, reaching the maximum for the 50/50 composition. Then, the increase in the Ge content lowered the $X_{c}$. According to bibliography, the high content of Ge allowed the diffusion of PCL molecules which hindered its crystallisation [59]. Therefore, a predominantly amorphous structure was expected for scaffolds with high Ge content.

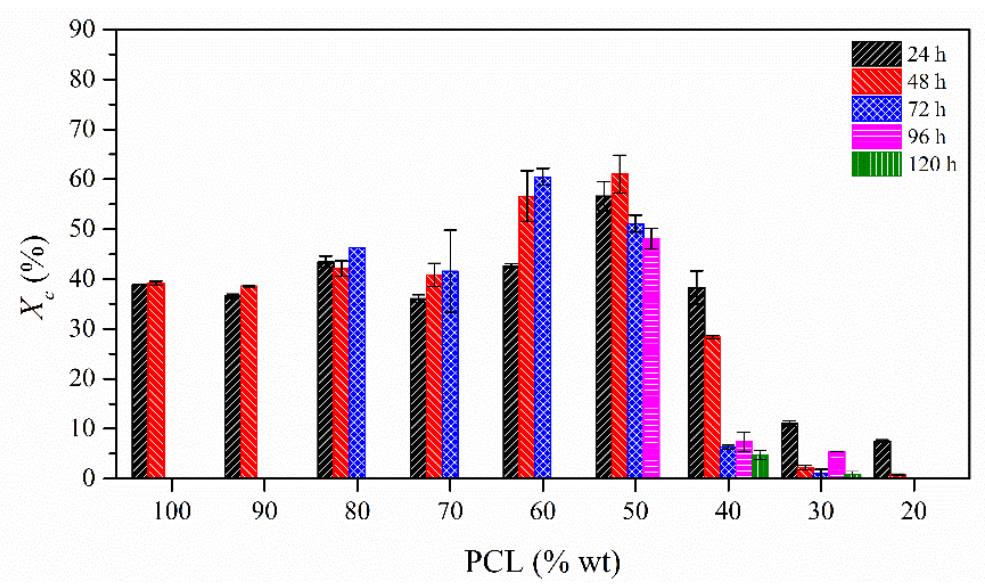

Figure 6. Crystallinity degree $\left(X_{c}\right)$ of the practicable electrospun scaffolds as a function of the scaffold composition and the dissolution time (D.T.).

The scaffolds with high PCL content, from 100/0 to 60/40, showed an increasing tendency of the $X_{c}$ as a function of the dissolution time, as a consequence of the hydrolytic degradation of the PCL chains. Shorter macromolecular segments with enhanced mobility were more capable of forming crystalline domains than longer segments. Shorter segments promoted enhanced crystallisation and orientation along the fibre axis [15]. However, scaffolds with high concentration of Ge, from 50/50 to 20/80, showed lower crystallinity degree as dissolution time increased. As observed in the previous section by the SEC analysis, the higher hydrolytic degradation of the PCL segments for these compositions seemed to result in too short PCL segments to develop substantial crystallisation. In addition, the lower molar mass and lower 
hydrodynamic radius found in previous sections corroborates the presumable diffusion of the PCL macromolecules into the Ge matrix, thus hindering the PCL crystallisation.

\subsubsection{Wettability}

Due to the biomedical purpose of these PCL/Ge scaffolds, an adequate wettability is of crucial importance, since it is related to the attachment, proliferation, migration and viability of cells [84], [85]. Therefore, the water contact angle of the practicable scaffolds is shown in Figure 7 as a function of the composition and the dissolution time.

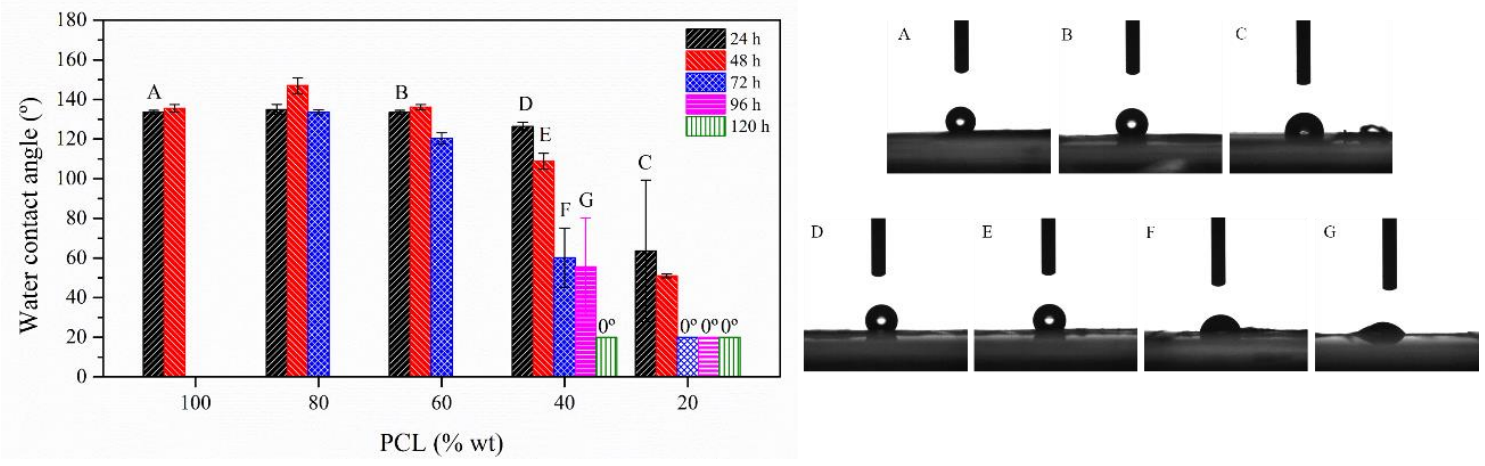

Figure 7. Water contact angle values (left) and selected drop pictures (right) of the practicable electrospun scaffolds as a function of the scaffold composition and the dissolution time (D.T.).

The pure PCL scaffold showed a contact angle of $134^{\circ}$, corroborating its hydrophobic behaviour [45]. A crystallised structure, along with the absence of available functional groups to interact with water molecules, reduced water affinity and resulted in high contact angles. On the one hand, PCL/Ge scaffolds with compositions ranging from 80/20 to 60/40 showed similar values than that of pure PCL. Although the Ge content increased, the PCL crystalline structure reduced the hydrophilic effect of the Ge. On the other hand, for PCL/Ge scaffolds with compositions between $40 / 60$ and 20/80, the water contact angle decreased, suggesting higher wettability. This fact can be correlated with the highly hydrophilic nature of the Ge macromolecules containing amide, amine and carboxyl groups available to interact with water molecules [86].

Concerning the effect of the dissolution time, it promoted an increase of the wettability of scaffolds, especially for the PCL/Ge scaffolds with compositions between 40/60 and 20/80. The highly hydrolytically degraded PCL segments with new carboxyl groups available to interact with water molecules favoured the wettability of the scaffolds [32]. Indeed, the scaffolds with high content of Ge after long dissolution time showed complete water impregnation $\left(0^{\circ}\right)$. 


\section{Conclusions}

Ultrathin nanofibrous scaffolds were successfully obtained by electrospinning of polycaprolactone (PCL) and gelatin (Ge) in a 1:1 formic/acetic acid solvent at PCL/Ge compositions ranging from $100 / 0$ to $20 / 80 \% \mathrm{wt}$ in steps of $10 \% \mathrm{wt}$. The influence of the dissolution time in the hydrolytic acid solvent was found to play a key role in the resultant molar mass, fibre morphology, crystallinity and wettability of the electrospun scaffolds.

The hydrolytic degradation of the ester bond of PCL segments was corroborated by the reduction of the intrinsic viscosity, molar mass and hydrodynamic radius as a function of the dissolution time. It reduced the number of effective entanglements between PCL segments. Accordingly, the fibre diameter of the electrospun scaffolds decreased as a function of the dissolution time for all the studied compositions. The fibre diameter remained in the nanoscale range for all the studied scaffolds, which is crucial to mimic the extra-cellular matrix size.

An effective tailoring of the PCL/Ge scaffolds was achieved through the defined acidic solvent system. These tailored scaffolds will show dissimilar performance at service conditions, affecting to factors such as the scaffold degradability or cell culture viability, among others. Future investigations will open up the possibility of studying the differentiation ability of cells onto these devices and study their biodegradation behaviour when implanted in vivo.

\section{Acknowledgements}

The Spanish Ministry of Economy and Competitiveness is acknowledged for the projects POLYCELL (ENE2014-53734-C2-1-R), POLYDECARBOCELL (ENE2017-86711-C3-1-R) and UPOV13-3E-1947. The Spanish Ministry of Education, Culture and Sports is thanked for the pre-doctoral FPU grant of O. Gil-Castell (FPU13/01916). Generalitat Valenciana is thanked for the APOSTD/2014/041 for J.D. Badia. S. Sánchez-Ballester is acknowledged for her kindness and aid with the wettability assays. IESMAT S.A. and Malvern Instruments Ltd. are recognised for their grateful collaboration.

\section{Bibliography}

[1] Z. Ma, M. Kotaki, R. Inai, and S. Ramakrishna, "Potential of nanofiber matrix as tissue-engineering scaffolds," Tissue Eng., vol. 11, no. 1, pp. 101-109, 2005.

[2] F. Khan, M. Tanaka, and S. R. Ahmad, "Fabrication of polymeric biomaterials: a strategy for tissue engineering and medical devices," J. Mater. Chem. B, vol. 3, no. 42, pp. 8224-8249, Oct. 2015.

[3] A. Haider, S. Haider, and I. K. Kang, "A comprehensive review summarizing the effect of electrospinning parameters and potential applications of nanofibers in biomedical and biotechnology," Arab. J. Chem., vol. In press, 2015.

[4] S. Agarwal, J. H. Wendorff, and A. Greiner, "Use of electrospinning technique for biomedical applications," Polymer (Guildf)., vol. 49, no. 26, pp. 5603-5621, 2008.

[5] D. I. Braghirolli, D. Steffens, and P. Pranke, "Electrospinning for regenerative medicine: a review of the main topics," Drug Discov. Today, vol. 19, no. 6, pp. 743-753, 2014.

[6] L. A. Smith and P. X. Ma, "Nano-fibrous scaffolds for tissue engineering," Colloids Surfaces B Biointerfaces, vol. 39, no. 3, pp. 125-131, 2004 
[7] S. Agarwal, A. Greiner, and J. H. Wendorff, "Functional materials by electrospinning of polymers," Prog. Polym. Sci., vol. 38, no. 6, pp. 963-991, Jun. 2013.

[8] B. Dhandayuthapani, Y. Yoshida, T. Maekawa, and D. S. Kumar, "Polymeric scaffolds in tissue engineering application: A review," Int. J. Polym. Sci., vol. 2011, no. ii, 2011.

[9] S. Stratton, N. B. Shelke, K. Hoshino, S. Rudraiah, and S. G. Kumbar, "Bioactive polymeric scaffolds for tissue engineering," Bioact. Mater., vol. 1, no. 2, pp. 93-108, Dec. 2016.

[10] D. M. Yoon and J. P. Fisher, "Natural and Synthetic Polymeric Scaffolds," in Biomedical Materials, R. Narayan, Ed. Springer, 2009, pp. 415-442.

[11] A. Asti and L. Gioglio, "Natural and synthetic biodegradable polymers: different scaffolds for cell expansion and tissue formation.," Int. J. Artif. Organs, vol. 37, no. 3, pp. 187-205, Mar. 2014.

[12] M. A. Woodruff and D. W. Hutmacher, "The return of a forgotten polymer-Polycaprolactone in the 21st century," Prog. Polym. Sci., vol. 35, no. 10, pp. 1217-1256, Oct. 2010.

[13] V. Thomas, M. V Jose, S. Chowdhury, J. F. Sullivan, D. R. Dean, and Y. K. Vohra, "Mechanomorphological studies of aligned nanofibrous scaffolds of polycaprolactone fabricated by electrospinning," J. Biomater. Sci. Polym. Ed., vol. 17, no. 9, pp. 969-984, Jan. 2006.

[14] A. Cipitria, A. Skelton, T. R. Dargaville, P. D. Dalton, and D. W. Hutmacher, "Design, fabrication and characterization of PCL electrospun scaffolds - a review," J. Mater. Chem., vol. 93, no. ii, pp. 1539-1550, 2011.

[15] X. Wang, H. Zhao, L. S. Turng, and Q. Li, "Crystalline morphology of electrospun poly(e-caprolactone) (PCL) nanofibers," Ind. Eng. Chem. Res., vol. 52, no. 13, pp. 4939-4949, 2013.

[16] L. Bosworth, P. Clegg, and S. Downes, "Electrospun nanofibres of polycaprolactone, and their use for tendon regeneration,” Int. J. Nano Biomater., vol. 1, no. 3, p. 263, 2008.

[17] K. H. Lee, H. Y. Kim, M. S. Khil, Y. M. Ra, and D. R. Lee, "Characterization of nano-structured poly $(\varepsilon-$ caprolactone) nonwoven mats via electrospinning," Polymer (Guildf)., vol. 44, no. 4, pp. 1287-1294, Feb. 2003.

[18] W. Ji, Y. Sun, F. Yang, J. J. J. P. van den Beucken, M. Fan, Z. Chen, and J. A. Jansen, "Bioactive electrospun scaffolds delivering growth factors and genes for tissue engineering applications.," Pharm. Res., vol. 28 , no. 6, pp. 1259-72, Jun. 2011.

[19] N. Bhardwaj and S. C. Kundu, "Electrospinning: A fascinating fiber fabrication technique," Biotechnol. Adv., vol. 28, no. 3, pp. 325-347, 2010.

[20] Q. Jiang, H. Xu, S. Cai, and Y. Yang, "Ultrafine fibrous gelatin scaffolds with deep cell infiltration mimicking 3D ECMs for soft tissue repair," J. Mater. Sci. Mater. Med., vol. 25, no. 7, pp. 1789-1800, Jul. 2014.

[21] E. J. Chong, T. T. Phan, I. J. Lim, Y. Z. Zhang, B. H. Bay, S. Ramakrishna, and C. T. Lim, "Evaluation of electrospun PCL/gelatin nanofibrous scaffold for wound healing and layered dermal reconstitution," Acta Biomater., vol. 3, no. 3 SPEC. ISS., pp. 321-330, May 2007.

[22] H. M. Powell and S. T. Boyce, "Engineered Human Skin Fabricated Using Electrospun Collagen-PCL Blends: Morphogenesis and Mechanical Properties," Tissue Eng. Part A, vol. 15, no. 8, pp. 2177-2187, Aug. 2009.

[23] R. S. Tığl1, N. M. Kazaroğlu, B. Mavış, and M. Gümüşderelioğlu, "Cellular Behavior on Epidermal Growth Factor (EGF)-Immobilized PCL/Gelatin Nanofibrous Scaffolds," J. Biomater. Sci. Polym. Ed., vol. 22, no. 1-3, pp. 207-223, Jan. 2011.

[24] L. H. Chong, M. M. Lim, and N. Sultana, "Fabrication and Evaluation of Polycaprolactone / Gelatin-Based Electrospun Nanofibers with Antibacterial Properties," vol. 2015, 2015.

[25] H. Duan, B. Feng, X. Guo, J. Wang, L. Zhao, G. Zhou, W. Liu, Y. Cao, and W. J. Zhang, "Engineering of epidermis skin grafts using electrospun nanofibrous gelatin/polycaprolactone membranes," Int. J. Nanomedicine, vol. 8, no. November, pp. 2077-2084, 2013.

[26] S. Gautam, C.-F. Chou, A. K. Dinda, P. D. Potdar, and N. C. Mishra, "Surface modification of nanofibrous polycaprolactone/gelatin composite scaffold by collagen type I grafting for skin tissue engineering," Mater. Sci. Eng. C, vol. 34, pp. 402-409, 2014.

[27] M. S. Kim, I. Jun, Y. M. Shin, W. Jang, S. I. Kim, and H. Shin, "The Development of Genipin-Crosslinked Poly(caprolactone) (PCL)/Gelatin Nanofibers for Tissue Engineering Applications," Macromol. Biosci., vol. 10, no. 1, pp. 91-100, Jan. 2010.

[28] S. Heydarkhan-Hagvall, K. Schenke-Layland, A. P. Dhanasopon, F. Rofail, H. Smith, B. M. Wu, R. Shemin, R. E. Beygui, and W. R. MacLellan, "Three-dimensional electrospun ECM-based hybrid scaffolds for cardiovascular tissue engineering," Biomaterials, vol. 29, no. 19, pp. 2907-2914, Jul. 2008.

[29] S. Pok, J. D. Myers, S. V. Madihally, and J. G. Jacot, "A multilayered scaffold of a chitosan and gelatin hydrogel supported by a PCL core for cardiac tissue engineering," Acta Biomater., vol. 9, no. 3, pp. 56305642, Mar. 2013.

[30] L. Ghasemi-Mobarakeh, M. P. Prabhakaran, M. Morshed, M.-H. Nasr-Esfahani, and S. Ramakrishna, "Electrospun poly( $\varepsilon$-caprolactone)/gelatin nanofibrous scaffolds for nerve tissue engineering," Biomaterials, vol. 29, no. 34, pp. 4532-4539, Dec. 2008.

[31] M. A. Alvarez-Perez, V. Guarino, V. Cirillo, and L. Ambrosio, "Influence of Gelatin Cues in PCL Electrospun Membranes on Nerve Outgrowth," Biomacromolecules, vol. 11, no. 9, pp. 2238-2246, Sep. 2010.

[32] D. Gupta, J. Venugopal, M. P. Prabhakaran, V. R. G. Dev, S. Low, A. T. Choon, and S. Ramakrishna, "Aligned and random nanofibrous substrate for the in vitro culture of Schwann cells for neural tissue 
engineering," Acta Biomater., vol. 5, no. 7, pp. 2560-2569, 2009.

[33] Y. Zhang, H. Ouyang, C. T. Lim, S. Ramakrishna, and Z.-M. Huang, "Electrospinning of gelatin fibers and gelatin/PCL composite fibrous scaffolds," J. Biomed. Mater. Res., vol. 72B, no. 1, pp. 156-165, Jan. 2005.

[34] I. Rajzer, E. Menaszek, R. Kwiatkowski, J. A. Planell, and O. Castano, "Electrospun gelatin/poly( $\varepsilon^{-}$ caprolactone) fibrous scaffold modified with calcium phosphate for bone tissue engineering," Mater. Sci. Eng. C, vol. 44, pp. 183-190, 2014.

[35] M. A. Alvarez Perez, V. Guarino, V. Cirillo, and L. Ambrosio, "In vitro mineralization and bone osteogenesis in poly(E-caprolactone)/gelatin nanofibers," J. Biomed. Mater. Res. Part A, vol. 100A, no. 11, pp. 3008-3019, Nov. 2012.

[36] A. K. Jaiswal, H. Chhabra, V. P. Soni, and J. R. Bellare, "Enhanced mechanical strength and biocompatibility of electrospun polycaprolactone-gelatin scaffold with surface deposited nanohydroxyapatite," Mater. Sci. Eng. C, vol. 33, no. 4, pp. 2376-2385, 2013.

[37] J. Huang, C. He, X. Liu, J. Xu, C. S. S. Tay, and S. Y. Chow, "Organic-inorganic nanocomposites from cubic silsesquioxane epoxides: direct characterization of interphase, and thermomechanical properties," Polymer (Guildf)., vol. 46, no. 18, pp. 7018-7027, Aug. 2005.

[38] R. Zheng, H. Duan, J. Xue, Y. Y. Liu, B. Feng, S. Zhao, Y. Zhu, Y. Y. Liu, A. He, W. Zhang, W. Liu, Y. Cao, and G. Zhou, "The influence of Gelatin/PCL ratio and 3-D construct shape of electrospun membranes on cartilage regeneration," Biomaterials, vol. 35, no. 1, pp. 152-164, Jan. 2014.

[39] J. . Deitzel, J. Kleinmeyer, D. Harris, and N. . Beck Tan, "The effect of processing variables on the morphology of electrospun nanofibers and textiles," Polymer (Guildf)., vol. 42, no. 1, pp. 261-272, Jan. 2001.

[40] X. Qin and D. Wu, "Effect of different solvents on poly(caprolactone) (PCL) electrospun nonwoven membranes," J. Therm. Anal. Calorim., vol. 107, no. 3, pp. 1007-1013, May 2012.

[41] P. Ginestra, E. Ceretti, and A. Fiorentino, "Electrospinning of Poly-caprolactone for Scaffold Manufacturing: Experimental Investigation on the Process Parameters Influence," Procedia CIRP, vol. 49, pp. 8-13, 2016.

[42] C. Erisken, D. M. Kalyon, and H. Wang, "Functionally graded electrospun polycaprolactone and $\beta$ tricalcium phosphate nanocomposites for tissue engineering applications," Biomaterials, vol. 29, no. 30, pp. 4065-4073, Oct. 2008.

[43] A. Gholipour Kanani and S. H. Bahrami, "Effect of Changing Solvents on Poly(-Caprolactone) Nanofibrous Webs Morphology," J. Nanomater., vol. 2011, pp. 1-10, 2011.

[44] L. A. Bosworth and S. Downes, "Acetone, a Sustainable Solvent for Electrospinning Poly( $\varepsilon$-Caprolactone) Fibres: Effect of Varying Parameters and Solution Concentrations on Fibre Diameter," J. Polym. Environ., vol. 20, no. 3, pp. 879-886, 2012.

[45] B. Feng, H. Tu, H. Yuan, H. Peng, and Y. Zhang, "Acetic-acid-mediated miscibility toward electrospinning homogeneous composite nanofibers of GT/PCL," Biomacromolecules, vol. 13, no. 12, pp. 3917-3925, Dec. 2012.

[46] N. S. Binulal, A. Natarajan, D. Menon, V. K. Bhaskaran, U. Mony, and S. V. Nair, "PCL-gelatin composite nanofibers electrospun using diluted acetic acid-ethyl acetate solvent system for stem cell-based bone tissue engineering," J. Biomater. Sci. Polym. Ed., vol. 25, no. 4, pp. 325-340, Mar. 2014.

[47] S. Sarabi-maneji, J. Scott, and D. J. Y. S. Pagé, "Process Optimization for the Electrospinning of Polycaprolactone Nanofibers Using Non-halogenated Solvents,” no. 82, pp. 1-8, 2014.

[48] L. Van der Schueren, B. De Schoenmaker, Ö. I. Kalaoglu, and K. De Clerck, "An alternative solvent system for the steady state electrospinning of polycaprolactone," Eur. Polym. J., vol. 47, no. 6, pp. 1256-1263, Jun. 2011.

[49] O. Gil-Castell, J. D. D. Badia, E. Strömberg, S. Karlsson, and A. Ribes-Greus, "Effect of the dissolution time into an acid hydrolytic solvent to tailor electrospun nanofibrous polycaprolactone scaffolds," Eur. Polym. J., vol. 87, pp. 174-187, 2017.

[50] N. Lavielle, A.-M. Popa, M. de Geus, A. Hébraud, G. Schlatter, L. Thöny-Meyer, and R. M. Rossi, "Controlled formation of poly( $\varepsilon$-caprolactone) ultrathin electrospun nanofibers in a hydrolytic degradationassisted process," Eur. Polym. J., vol. 49, no. 6, pp. 1331-1336, Jun. 2013.

[51] E. Browning, “Toxic solvents: a review," Brit. J. Ind. Med, vol. 16, 1959.

[52] J. Nam, Y. Huang, S. Agarwal, and J. Lannutti, "Materials selection and residual solvent retention in biodegradable electrospun fibers,” J. Appl. Polym. Sci., vol. 107, no. 3, pp. 1547-1554, Feb. 2008.

[53] N. Choktaweesap, K. Arayanarakul, D. Aht-ong, C. Meechaisue, and P. Supaphol, "Electrospun Gelatin Fibers: Effect of Solvent System on Morphology and Fiber Diameters," Polym. J., vol. 39, no. 6, pp. 622631, Jun. 2007.

[54] S.-Y. Gu, Z.-M. Wang, J. Ren, and C.-Y. Zhang, "Electrospinning of gelatin and gelatin/poly(l-lactide) blend and its characteristics for wound dressing," Mater. Sci. Eng. C, vol. 29, no. 6, pp. 1822-1828, Aug. 2009.

[55] J.-H. Song, H.-E. Kim, and H.-W. Kim, "Production of electrospun gelatin nanofiber by water-based cosolvent approach,” J. Mater. Sci. Mater. Med., vol. 19, no. 1, pp. 95-102, Jan. 2008.

[56] I. H. L. Pereira, E. Ayres, L. Averous, G. Schlatter, A. Hebraud, S. T. O. L. Mendes, and R. L. Oréfice, "Elaboration and characterization of coaxial electrospun poly(??-caprolactone)/gelatin nanofibers for biomedical applications," Adv. Polym. Technol., vol. 33, no. S1, pp. 1-10, 2014.

[57] P. Denis, J. Dulnik, and P. Sajkiewicz, "Electrospinning and Structure of Bicomponent Polycaprolactone/Gelatin Nanofibers Obtained Using Alternative Solvent System," Int. J. Polym. Mater. 
Polym. Biomater., vol. 64, no. 7, pp. 354-364, 2014.

[58] J. Dulnik, P. Denis, P. Sajkiewicz, D. Kołbuk, and E. Choińska, "Biodegradation of bicomponent $\mathrm{PCL} /$ gelatin and PCL/collagen nanofibers electrospun from alternative solvent system," Polym. Degrad. Stab., vol. 130, no. November, pp. 10-21, 2016.

[59] D. Kolbuk, P. Sajkiewicz, P. Denis, and E. Choinska, "Investigations of polycaprolactone/gelatin blends in terms of their miscibility," Bull. Polish Acad. Sci. Tech. Sci., vol. 61, no. 3, pp. 629-632, 2013.

[60] A. Arinstein, M. Burman, O. Gendelman, and E. Zussman, "Effect of supramolecular structure on polymer nanofibre elasticity," Nat. Nanotechnol., vol. 2, no. 1, pp. 59-62, Jan. 2007.

[61] H. Cai, V. Dave, R. A. Gross, and S. P. McCarthy, "Effects of physical aging, crystallinity, and orientation on the enzymatic degradation of poly(lactic acid)," J. Polym. Sci. Part B Polym. Phys., vol. 34, no. 16, pp. 2701-2708, Nov. 1996.

[62] J. Gaumer, A. Prasad, D. Lee, and J. Lannutti, "Structure-function relationships and source-to-ground distance in electrospun polycaprolactone," Acta Biomater., vol. 5, no. 5, pp. 1552-1561, Jun. 2009.

[63] V. Guarino, V. Cirillo, P. Taddei, M. A. Alvarez-Perez, and L. Ambrosio, "Tuning Size Scale and Crystallinity of PCL Electrospun Fibres via Solvent Permittivity to Address hMSC Response," Macromol. Biosci., vol. 11, no. 12, pp. 1694-1705, Dec. 2011.

[64] M. J. Jenkins and K. L. Harrison, "The effect of crystalline morphology on the degradation of polycaprolactone in a solution of phosphate buffer and lipase," Polym. Adv. Technol., vol. 19, no. 12, pp. 1901-1906, Dec. 2008.

[65] J. L. Lowery, N. Datta, and G. C. Rutledge, "Effect of fiber diameter, pore size and seeding method on growth of human dermal fibroblasts in electrospun poly(e-caprolactone) fibrous mats," Biomaterials, vol. 31, no. 3, pp. 491-504, Jan. 2010.

[66] J. E. Mark, Properties of Polymers Handbook. Springer, 2007.

[67] S. Gautam, A. K. Dinda, and N. C. Mishra, "Fabrication and characterization of PCL/gelatin composite nanofibrous scaffold for tissue engineering applications by electrospinning method," Mater. Sci. Eng. C, vol. 33, no. 3, pp. 1228-1235, 2013.

[68] Y. Wan, X. Lu, S. Dalai, and J. Zhang, "Thermophysical properties of polycaprolactone/chitosan blend membranes," Thermochim. Acta, vol. 487, no. 1, pp. 33-38, 2009.

[69] C. Peña, K. de la Caba, A. Eceiza, R. Ruseckaite, and I. Mondragon, "Enhancing water repellence and mechanical properties of gelatin films by tannin addition," Bioresour. Technol., vol. 101, no. 17, pp. 68366842, 2010.

[70] K. Lewandowska, "Miscibility and thermal stability of poly(vinyl alcohol)/chitosan mixtures," Thermochim. Acta, vol. 493, no. 1, pp. 42-48, 2009.

[71] C. S. Ki, D. H. Baek, K. D. Gang, K. H. Lee, I. C. Um, and Y. H. Park, "Characterization of gelatin nanofiber prepared from gelatin-formic acid solution,” Polymer (Guildf)., vol. 46, no. 14, pp. 5094-5102, Jun. 2005.

[72] R. Muthuraj, M. Misra, and A. K. Mohanty, "Hydrolytic degradation of biodegradable polyesters under simulated environmental conditions," J. Appl. Polym. Sci., vol. 132, no. 27, p. n/a-n/a, Jul. 2015.

[73] X. He, B. Feng, C. Huang, H. Wang, Y. Ge, R. Hu, M. Yin, Z. Xu, W. Wang, W. Fu, and J. Zheng, "Electrospun gelatin/polycaprolactone nanofibrous membranes combined with a coculture of bone marrow stromal cells and chondrocytes for cartilage engineering," Int. J. Nanomedicine, vol. 10, pp. 2089-2099, 2015.

[74] J. Xue, B. Feng, R. Zheng, Y. Lu, G. Zhou, W. Liu, Y. Cao, Y. Zhang, and W. J. Zhang, "Engineering earshaped cartilage using electrospun fibrous membranes of gelatin/polycaprolactone," Biomaterials, vol. 34, no. 11, pp. 2624-2631, 2013.

[75] D. . Chen, J. . Bei, and S. . Wang, "Polycaprolactone microparticles and their biodegradation," Polym. Degrad. Stab., vol. 67, no. 3, pp. 455-459, 2000.

[76] L. Santonja-Blasco, R. Moriana, J. D. Badía, and A. Ribes-Greus, "Thermal analysis applied to the characterization of degradation in soil of polylactide: I. Calorimetric and viscoelastic analyses," Polym. Degrad. Stab., vol. 95, no. 11, pp. 2185-2191, Nov. 2010.

[77] J. D. Badia, E. Strömberg, S. Karlsson, and A. Ribes-Greus, "Material valorisation of amorphous polylactide. Influence of thermo-mechanical degradation on the morphology, segmental dynamics, thermal and mechanical performance," Polym. Degrad. Stab., vol. 97, no. 4, pp. 670-678, Apr. 2012.

[78] O. Gil-Castell, J. D. Badia, T. Kittikorn, E. Strömberg, M. Ek, S. Karlsson, A. Ribes-Greus, E. Strömberg, M. Ek, S. Karlsson, and A. Ribes-Greus, "Impact of hydrothermal ageing on the thermal stability, morphology and viscoelastic performance of PLA/sisal biocomposites," Polym. Degrad. Stab., vol. 132, pp. 87-96, Mar. 2016.

[79] J. D. Badia, T. Kittikorn, E. Strömberg, L. Santonja-Blasco, A. Martínez-Felipe, A. Ribes-Greus, M. Ek, and S. Karlsson, "Water absorption and hydrothermal performance of PHBV/sisal biocomposites," Polym. Degrad. Stab., vol. 108, pp. 166-174, Oct. 2014.

[80] O. Gil-Castell, J. D. Badia, T. Kittikorn, E. Strömberg, A. Martínez-Felipe, M. Ek, S. Karlsson, and A. Ribes-Greus, "Hydrothermal ageing of polylactide/sisal biocomposites. Studies of water absorption behaviour and Physico-Chemical performance," Polym. Degrad. Stab., vol. 108, pp. 212-222, Oct. 2014.

[81] J. D. Badia, L. Santonja-Blasco, A. Martínez-Felipe, and A. Ribes-Greus, "Hygrothermal ageing of reprocessed polylactide,” Polym. Degrad. Stab., vol. 97, no. 10, pp. 1881-1890, Oct. 2012.

[82] J. D. Badia, E. Strömberg, T. Kittikorn, M. Ek, S. Karlsson, and A. Ribes-Greus, "Relevant factors for the eco-design of polylactide/sisal biocomposites to control biodegradation in soil in an end-of-life scenario," 
Polym. Degrad. Stab., vol. 143, pp. 9-19, Sep. 2017.

[83] J. D. Badia, E. Strömberg, S. Karlsson, and A. Ribes-Greus, "The role of crystalline, mobile amorphous and rigid amorphous fractions in the performance of recycled poly (ethylene terephthalate) (PET)," Polym. Degrad. Stab., vol. 97, no. 1, pp. 98-107, Jan. 2012.

[84] K. Zhang, H. Wang, C. Huang, Y. Su, X. Mo, and Y. Ikada, "Fabrication of silk fibroin blended P(LLA-CL) nanofibrous scaffolds for tissue engineering," J. Biomed. Mater. Res. A, vol. 96, no. 3, pp. 984-993, 2010.

[85] A. Mikos, M. Lyman, L. Freed, and R. Langer, "Wetting of poly(L-lactic acid) and poly(DL-lactic-coglycolic acid) foams for tissue culture," Biomaterials, vol. 15, no. 1, pp. 55-58, 1994.

[86] W. Fu, Z. Liu, B. Feng, R. Hu, X. He, H. Wang, M. Yin, H. Huang, H. Zhang, and W. Wang, "Electrospun gelatin/PCL and collagen/PLCL scaffolds for vascular tissue engineering," Int. J. Nanomedicine, vol. 9, no. 1, pp. 2335-2344, 2014. 
ANNEX - OPEN ACCESS POLICIES

SHERPA/R॰MEO

opening access to research

Search - Publisher copyright policies \& self-archiving One jourmal found when searched for: 0014-3057

Journat: European Polymer Journal assw 0014-305

RoMEO: THS S a ROLEEO greten poum

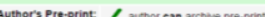

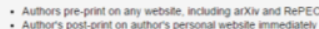

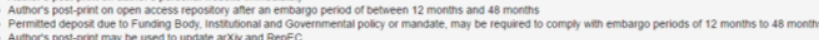

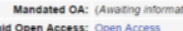

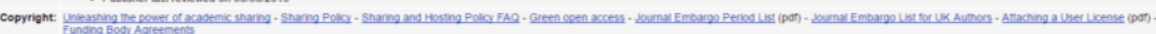

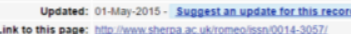

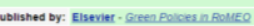

This summary is for the journals default policles, and changes or exceptions can offen be negotiated by authors.
All information is correct to the best of our knowledge but should not be reliled upon for legal advice. 